\title{
Synthesis of Conjugated Molecules Based on Dithienopyrrole Derivatives and Pyrene as Chemosensor for Mesotrione Detection
}

\author{
Bao K. Doan, ${ }^{a}$ Cam H. T. Nguyen, ${ }^{a}$ Thao T. Bui, ${ }^{a}$ Tung V. T. Tran, ${ }^{a}$ Ha P. K. Huynh, ${ }^{b}$ \\ Quoc-Thiet Nguyen, ${ }^{c}$ Son T. Cu, ${ }^{c}$ Le-Thu T. Nguyen, ${ }^{d}$ Chau D. Tran, ${ }^{d}$ Phong T. Mai, ${ }^{b}$ \\ Hai L. Tran ${ }^{b}$ and Ha T. Nguyen ${ }^{\circledR} * a, d$ \\ ${ }^{a}$ National Key Laboratory of Polymer and Composite Materials, \\ Ho Chi Minh City University of Technology, Vietnam National University (VNU-HCM), \\ 268 Ly Thuong Kiet, District 10, 70000 Ho Chi Minh City, Vietnam \\ ${ }^{b}$ Faculty of Chemical Engineering, Ho Chi Minh City University of Technology, \\ Vietnam National University, 268 Ly Thuong Kiet, District 10, 70000 Ho Chi Minh City, Vietnam \\ 'Institute of Applied Materials Science, Vietnam Academy of Science and Technology, \\ 01 TL29, District 12, 70000 Ho Chi Minh City, Vietnam \\ ${ }^{d}$ Faculty of Materials Technology, Ho Chi Minh City University of Technology, \\ Vietnam National University, 268 Ly Thuong Kiet, District 10, 70000 Ho Chi Minh City, Vietnam
}

The conjugated molecules based on pyrene and dithienopyrrole derivatives including 4-(2-ethylhexyl)-2-(pyren-1-yl)-4H-dithieno[3,2-b:2',3'-d]pyrrole (EP4HP) and 4-(2-ethylhexyl)2,6-di(pyren-1-yl)-4H-dithieno[3,2-b:2',3'-d]pyrrole (EDP4HP) have been successfully synthesized via $\mathrm{C}-\mathrm{H}$ direct arylation reaction. The structures of these conjugated molecules were determined via nuclear magnetic resonance and Fourier-transform infrared spectroscopy (FTIR). The optical properties of conjugated molecules were evaluated via ultraviolet visible (UV-Vis) and fluorescence spectroscopies. The conjugated molecules exhibited the efficient fluorescence quenching toward herbicide mesotrione as nitroaromatic pesticides that could be promising candidates as the chemosensor for tracing of nitroaromatic pesticides.

Keywords: conjugated molecules, pyrene, dithieno[3,2-b:2, $\left.3^{\prime}-d\right]$ pyrrole, chemosensor, fluorescent molecules

\section{Introduction}

Pesticides are widely used in agricultural production, and the pesticides demand is increasing due to population growth leading to a priority in promoting high agricultural productivity. The ingredients of pesticides are chemicals that can control pests or plant growth which have become effective tools in boosting agricultural productivity. However, pesticides are also the world's leading concern in food safety, which are the main cause of more than 200,000 deaths each year. ${ }^{1}$ Furthermore, the health concerns associated with the consumption of products containing pesticides are becoming more noticeable in developing

*e-mail: nguyentranha@hcmut.edu.vn

Editor handled this article: Brenno A. D. Neto (Associate) countries due to the lack of knowledge and understanding of farmers using pesticides in cultivation.

At present, many pesticides with nitro-aromatic compounds (NACs, Figure 1) such as parathion, nitrofen, 4,6-dinitro-o-cresol and mesotrione have been commonly used to protect crops. NACs pesticides are one of the leading causes of environmental pollution due to their high biological activity and toxicity. ${ }^{2}$ Most pesticides do not distinguish between plants and pests, they have the potential to harm humans, animals and other living organisms if used incorrectly. One of the most crucial ways of diminishing potential risks to the environment and the health of humans is the monitoring of these pesticide residues. Up to now, the methods of detecting pesticides have made remarkable progress. Typically, it is used traditional chromatographic detection methods, including gas chromatography (GC), ${ }^{3}$ high performance liquid chromatography (HPLC) ${ }^{4}$ and gas 
<smiles>COP(=S)(OC)Oc1ccc([N+](=O)[O-])cc1</smiles>

Parathion methyl<smiles>COP(=S)(OC)Oc1ccc([N+](=O)[O-])c(C)c1</smiles>

Fenitrothion<smiles>CS(=O)(=O)c1ccc(C(=O)C2C(=O)CCCC2=O)c([N+](=O)[O-])c1</smiles>

Mesotrione<smiles>Nc1c([N+](=O)[O-])cccc1[N+](=O)[O-]</smiles>

2,6-dinitroaniline<smiles>CCCN(CCC)c1c([N+](=O)[O-])cc(S(C)(=O)=O)cc1[N+](=O)[O-]</smiles>

Nitralin<smiles>CCC(CC)Nc1c([N+](=O)[O-])cc(C)c(C)c1[N+](=O)[O-]</smiles>

Pendimethalin<smiles>CCOc1cc(Oc2ccc(C(F)(F)F)cc2Cl)ccc1[N+](=O)[O-]</smiles><smiles>COC(=O)c1cc(Oc2ccc(Cl)cc2Cl)ccc1[N+](=O)[O-]</smiles>

Figure 1. Structures of some nitro-aromatic pesticides.

chromatography mass spectrometry (GC-MS), ${ }^{5}$ besides other methods such as electrochemical analysis, ${ }^{6}$ biosensors based on acetylcholinesterase (AChE), ${ }^{7}$ etc. All of these methods have their own advantages and disadvantages, in which the chromatographic method shows accurate and high sensitivity but requires expensive equipment investment, time-consuming, complicated operation and poor portability.

In recent years, a fluorescence-based method has been approached due to better efficiency, simplicity, fast, and reliability. This technique is due to the response of colorimetric and fluorimetric properties that are mainly concentrated on the fluorescence sensors. Optical fluorescence sensors based on photoluminescence (PL) quenching have been attended due to their selectivity, low cost and ease of operation. ${ }^{8}$ For example, Zhao et al. ${ }^{9}$ synthesized a pyranine for paraquat sensor based on the fluorescent turn-off method. Under the optimized conditions, this technique is sensitive, selective, and could be used for paraquat detection in the real sample. $\mathrm{Hu}$ et al. ${ }^{10}$ also reported a colorimetric chemosensor based on gold nanoparticles (AuNPs) due to the inhibition of the peroxidase-like activity for rapid detection of dimethoate pesticide in agricultural products. Optical chemosensing methodology based on functional materials/ nanomaterials including conjugated molecules/polymers, macrocycle and metal-organic frameworks have shown great potential for sensitive and selective detection of pesticide. Mallard-Favier et al. ${ }^{11}$ synthesized a novel peracetylated cyclodextrin trimer containing three fluorescent 1,2,3-triazole linkers that exhibited an excellent emission fluorescence by the addition of pendimethalin with extremely low detection limits $(0.8-4 \mu \mathrm{M})$. Kumar et al. ${ }^{12}$ synthesized a luminescent nanocrystal metal-organic framework (NMOF1) for chemosensing of organophosphate pesticides. Hergert et al. ${ }^{13}$ reported the molecular chain effect in phenylene ethynylene oligomers to detect insecticides showing a significant increase in Stern-Volmer quenching. A molecularly imprinted polymers (MIP)-based fluorescent probe was synthesized by Sun et al..$^{14}$ using biomass-modified carbon quantum dots (CQDs) which are encapsulated into MIPs, for rapid and sensitive mesotrione detection. Zhang et al. ${ }^{15}$ reported that a carbazole-containing polymer with significant inherent porosity exhibited apparent fluorescence quenching upon increasing the concentration of trifluralin. However, a lot of the conjugated polymers/oligomers applied for pesticide probe have normally been synthesized via multiple intricate steps that lead to a consideration in the purification of the products and that the lack of straightforward access to such polymers/oligomers can preclude their widespread usage.

In general, fluorescence-based chemosensors for NACs pesticides detection have been created centered on the Forster resonance energy transfer where the conjugated molecules act as a donor chromophore that transfers energy to an acceptor chromophore via nonradiative dipole-dipole coupling giving a dramatical increase in the fluorescence-quenching efficiency and sensitivity improvement. In fluorescence resonance energy transfer (FRET), the fluorophore (donor) absorbs the excitation energy of the incident light and then transfers this energy to a nearby chromophore (acceptor). Energy transfer manifests through quenching of the donor fluorescence or reducing the excited state lifetime accompanied by an 
increase in the acceptor fluorescence intensity. ${ }^{16}$ However, the development of fluorescence sensors is limited due to fluorescence quenching from unstable substrates or probes. ${ }^{17}$ Most organic fluorescence molecules suffer from aggregation caused quenching (ACQ), which is responsible for low fluorescence emission at high concentrations or solid-state. Over years, lots of methods in various fields have been approved to decrease ACQ effects, ${ }^{18-21}$ but the effect is not indefectible. Recently, the aggregation-induced emission (AIE) characteristics of fluorescent molecules have been researched. ${ }^{22,23}$ AIE phenomenon is due to the restriction of intramolecular rotation. ${ }^{24}$ Its unique properties provide AIE probes with significant advantages including lower background and higher light stability. ${ }^{25}$

Pyrene and its derivatives are well known as an excellent product for being employed as fluorescent compound because of their electron rich molecules. ${ }^{26-28}$ Pyrene has the advantage of intense emission with long lifetime values, tendency to form excimers, and high sensitivity to electron-deficient molecules. ${ }^{29}$ Moreover, pyrene owns the $\pi$-conjugated plane structure which gets it easier to associate with NACs via $\pi-\pi$ interaction. ${ }^{30}$ Over the years, many pyrene-based chemosensors have been developed to detect different NACs. ${ }^{31-33}$ On the other hand, dithienopyrrole derivatives are having better $\pi$-conjugation and lower ionization potential by electron donating molecules ${ }^{34}$ so they are suitable for making excellent donor materials. Therefore, the combination of pyrene and dithienopyrrole derivatives is expected to be potential donor molecules for NACs pesticide detection.

\section{Experimental}

\section{Materials}

$N$-Bromosuccinimide (99\%), pyrene (98\%), 3,3'-dibromo-2,2'-bithiophene (98\%) and 2-ethylhexylamine (98\%) were purchased from Acros Organic, Geel, Belgium. Mesotrione (98\%), tris(dibenzylideneacetone)dipalladium(0) $\left(\mathrm{Pd}_{2}(\mathrm{dba})_{3}, 98 \%\right), 2,2$ '-bis (diphenylphosphino)-1,1'-binaphthyl (98\%) were ordered from Sigma-Aldrich, St. Louis, Missouri, USA. Tricyclohexylphosphine tetrafluoroborate $\left(\mathrm{P}(\mathrm{Cy})_{3} \cdot \mathrm{HBF}_{4}\right.$, $97 \%)$, sodium tert-butoxide $(\mathrm{NaO} t$-Bu, $97 \%)$, pivalic acid (PivOH, 99\%), palladium(II) acetate $\left(\mathrm{Pd}(\mathrm{OAc})_{2}, 98 \%\right)$ and cesium carbonate $\left(\mathrm{Cs}_{2} \mathrm{O}_{3}, 99 \%\right)$ were purchased from Sigma-Aldrich, St. Louis, Missouri, USA. Potassium carbonate $\left(\mathrm{K}_{2} \mathrm{CO}_{3}, 99 \%\right)$ was purchased from Acros Organic (Geel, Belgium) and used as received. Toluene (99.5\%) and chloroform $\left(\mathrm{CHCl}_{3}, 99.5 \%\right)$ were purchased from Acros Organic (Geel, Belgium). Anhydrous dimethylformamide
(DMF, 99\%), dichloromethane (DCM, 99.8\%) and hexane (99\%) were ordered from Acros Organic (Geel, Belgium) and used as received.

\section{Measurements}

Fourier-transform infrared (FTIR) spectra were recorded from $\mathrm{KBr}$ disk on the FTIR Bruker Tensor 27 (Bruker, Massachusetts, USA). Elemental analyses were performed by Elemental Analyzer (Costech ECS 4010, NC Technologies, Milan, Italy). ${ }^{1} \mathrm{H}$ and ${ }^{13} \mathrm{C}$ nuclear magnetic resonance (NMR) spectra were recorded in deuterated chloroform $\left(\mathrm{CDCl}_{3}\right)$ with tetramethylsilane (TMS) as an internal reference, on a Bruker Avance $500 \mathrm{MHz}$ (Bruker, Massachusetts, USA).

UV-Vis spectra were recorded on Agilent $8453 \mathrm{UV}-\mathrm{Vis}$ spectrometer (Agilent, CA, USA) over a wavelength range of 200-1100 nm.

Fluorescence spectra were performed on Cary Eclipse Fluorescence Spectrophotometer (Agilent, CA, USA) over the wavelength range of $350-900 \mathrm{~nm}$. The solutions were excited at the wavelength of $365 \mathrm{~nm}$.

The AUTOLAB equipment (Utrecht, Netherlands) was used to measure the electrochemical properties of molecules. The AUTOLAB software is NOVA 1.11. The electrochemical experiments used an $\mathrm{Au}$ disk working electrode, a Pt as counter electrode and an $\mathrm{Ag} / \mathrm{Ag}^{+}$reference electrode. The solutions were prepared with $0.1 \mathrm{M} \mathrm{TBAPF}_{6}$ (tetrabutylammonium hexafluorophosphate) in acetonitrile. $\mathrm{Ag} / \mathrm{Ag}^{+}$reference electrode (0.1 $\mathrm{M} \mathrm{AgNO}_{3} / 0.1 \mathrm{M} \mathrm{TBAPF}_{6}$ in $\mathrm{CH}_{3} \mathrm{CN}$; $0.320 \mathrm{~V}$ vs. $\mathrm{SCE}$ ) was used as a reference potential.

Synthesis of 4-(2-ethylhexyl)-4H-dithieno[3,2-b:2',3'-d] pyrrole (EDP) (1)

To a solution of $\mathrm{Pd}_{2}(\mathrm{dba})_{3}(94.25 \mathrm{mg}, 0.10 \mathrm{mmol})$, 2,2'-bis(diphenylphosphino)-1,1'-binaphthyl (BINAP, $256.36 \mathrm{mg}, 0.41 \mathrm{mmol}$ ) and $\mathrm{NaO} t-\mathrm{Bu}(725.36 \mathrm{mg}$, $7.55 \mathrm{mmol})$ in toluene $(8 \mathrm{~mL})$ in a round bottom flask were added 3,3'-dibromo-2,2'-bithiophene (1111.78 mg, $3.43 \mathrm{mmol}$ ) and 2-ethylhexylamine (443.44 mg, $3.43 \mathrm{mmol}$ ) under nitrogen atmosphere. Then, the mixture was performed by three freeze-pump-thaw cycles to remove completely air and charged nitrogen in the reaction. Then, the reaction was performed at $110{ }^{\circ} \mathrm{C}$ under $\mathrm{N}_{2}$ for $24 \mathrm{~h}$. Then, the reaction mixture was cooled down to room temperature, chloroform was used to extract the mixture reaction three times $(3 \times 20 \mathrm{~mL})$. The mixture was washed with $10 \% \mathrm{NaCl}(150 \mathrm{~mL})$, dried over $\mathrm{K}_{2} \mathrm{CO}_{3}$. The organic solvent was evacuated via evaporation to 
obtain the crude product that subsequently was purified via column chromatography using a silica gel column with hexane. Finally, the compound was dried in a vacuum at $50{ }^{\circ} \mathrm{C}$ to obtain the yellow viscous liquid (yield $=56 \%$ ). ${ }^{1} \mathrm{H}$ NMR (500 MHz, $\left.\mathrm{CDCl}_{3}\right) \delta 7.04$ (d, J $\left.5.2 \mathrm{~Hz}, 2 \mathrm{H}\right), 6.90$ $(\mathrm{d}, J 5.3 \mathrm{~Hz}, 2 \mathrm{H}), 3.98(\mathrm{~m}, 2 \mathrm{H}), 1.87(\mathrm{~m}, 1 \mathrm{H}), 1.22(\mathrm{~m}$, $8 \mathrm{H}), 0.82(\mathrm{~m}, 6 \mathrm{H}) ;{ }^{13} \mathrm{C} \mathrm{NMR}\left(125 \mathrm{MHz}, \mathrm{CDCl}_{3}\right) \delta 10.69$, 14.01, 22.98, 24.08, 28.70, 30.71, 40.50, 51.38, 111.09, $114.59,122.70,145.34$; elemental analysis for $\mathrm{C}_{16} \mathrm{H}_{21} \mathrm{NS}_{2}$ : calculated: C, 65.93; H, 7.26; N, 4.81; S, 22.00; found: C, $66.20 ; \mathrm{H}, 7.21 ; \mathrm{N}, 4.87 ; \mathrm{S}, 21.72$.

\section{Synthesis of 1-bromopyrene (2)}

Pyrene (1.00 g, $4.94 \mathrm{mmol}$ ) was dissolved to $20 \mathrm{~mL}$ of anhydrous dimethylformamide (DMF) in a $100 \mathrm{~mL}$ round bottom flask. The reaction was cooled to $0{ }^{\circ} \mathrm{C}$, then $N$-bromosuccinimide (NBS) (0.97 g, $5.43 \mathrm{mmol})$ was added to the reaction slowly. Then, the reaction mixture was reacted at room temperature overnight. After that, the cold water was added to the reaction which was then extracted with chloroform $(60 \mathrm{~mL})$. The mixture layer was washed with brine $(150 \mathrm{~mL})$ and dried over anhydrous $\mathrm{K}_{2} \mathrm{CO}_{3}$. The solvent was evacuated by evaporation and the product was precipitated in cold hexane to obtain the white powder. The white powder was subsequently dried in a vacuum oven at $50{ }^{\circ} \mathrm{C}$ for $24 \mathrm{~h}$ (yield $=94 \%$ ). It should be noted that the bromination process has a selectivity for the proton at position 1 of pyrene over other protons. ${ }^{1} \mathrm{H} \mathrm{NMR}$ $\left(500 \mathrm{MHz}, \mathrm{CDCl}_{3}\right) \delta 8.45(\mathrm{~d}, J 8.5 \mathrm{~Hz}, 1 \mathrm{H}), 8.25-8.21(\mathrm{~m}$, $3 \mathrm{H}), 8.19$ (s, 1H), 8.07-8.01 (m, 4H); ${ }^{13} \mathrm{C} \mathrm{NMR} \mathrm{(125} \mathrm{MHz,}$ $\left.\mathrm{CDCl}_{3}\right) \delta 121.1,124.3,125.2,126.4,130.5,133.7,132.2$, 133.4; elemental analysis for $\mathrm{C}_{16} \mathrm{H}_{9} \mathrm{Br}$ : calculated: $\mathrm{C}, 68.35$; H, 3.23; Br, 28.42. Found: C, 67.75; H, 3.35; Br, 28.90.

Synthesis of 4-(2-ethylhexyl)-2-(pyren-1-yl)-4H-dithieno $[3,2-b: 2,3$ '-d]pyrrole (EP4HP) and 4-(2-ethylhexyl)2,6-di(pyren-1-yl)-4H-dithieno[3,2-b:2,3'-d]pyrrole (EDP4HP)

$\mathrm{Pd}(\mathrm{OAc})_{2}(6.74 \mathrm{mg}, 0.03 \mathrm{mmol}), \mathrm{Cs}_{2} \mathrm{CO}_{3}(283.46 \mathrm{mg}$, $0.87 \mathrm{mmol}), \mathrm{P}(\mathrm{Cy})_{3} . \mathrm{HBF}_{4}(22.09 \mathrm{mg}, 0.06 \mathrm{mmol})$ and $\mathrm{PivOH}$ (17.36 $\mathrm{mg}, 0.17 \mathrm{mmol}$ ) were dissolved in $8 \mathrm{~mL}$ toluene in a round bottom flask. Then, 1-bromopyrene $(202.43 \mathrm{mg}$, $0.72 \mathrm{mmol})$ and EDP $(84.53 \mathrm{mg}, 0.29)$ were added into the mixture reaction under nitrogen. The reaction mixture was performed by three freeze-pump-thaw cycles to remove completely air and charged with nitrogen. Then, the reaction was reacted at $110{ }^{\circ} \mathrm{C}$ under $\mathrm{N}_{2}$ for $48 \mathrm{~h}$. After that, the reaction mixture was cooled down to room temperature and extracted with chloroform three times $(3 \times 20 \mathrm{~mL})$. Then, the mixture was washed with $10 \% \mathrm{NaCl}(150 \mathrm{~mL})$, dried over $\mathrm{K}_{2} \mathrm{CO}_{3}$ and filtrated via funnel. The solvent was evaporated via rotary evaporation equipment to obtain the crude product. The products were purified via column chromatography on a silica gel column using a mixture of hexane and dichloromethane as eluent $(v / v=40: 1)$. Finally, the compound was dried in a vacuum oven at $50{ }^{\circ} \mathrm{C}$ to obtain the dark grey powder $(\mathrm{EP} 4 \mathrm{HP}$, yield $=45.8 \%)$ and the orange powder $(\mathrm{EDP} 4 \mathrm{HP}$, yield $=52 \%)$.

\section{EP4HP}

${ }^{1} \mathrm{H}$ NMR (500 MHz, $\left.\mathrm{CDCl}_{3}\right) \delta 8.64(\mathrm{~d}, J 9.3 \mathrm{~Hz}, 1 \mathrm{H})$, 8.22-8.01 (m, 8H), 7.29 (s, 1H), 7.18 (d, J 5.3 Hz, 1H), 7.05 (d, J $5.3 \mathrm{~Hz}, 1 \mathrm{H}), 4.16(\mathrm{~d}, J 7.2,4.1 \mathrm{~Hz}, 2 \mathrm{H}), 2.04(\mathrm{~m}, 1 \mathrm{H})$, 1.56-1.39 (m, 8H), 0.95-0.84 (m, 6H); ${ }^{13} \mathrm{C} \mathrm{NMR} \mathrm{(125} \mathrm{MHz,}$ $\left.\mathrm{CDCl}_{3}\right) \delta 10.69,14.01,22.98,24.08,28.70,30.71,40.50$, 51.38, 121.0, 122.7, 125.3, 125.8, 126.7, 127.5, 127.9, $128.3,128.8,130.5,132.2,133.3,141.1$; elemental analysis for $\mathrm{C}_{32} \mathrm{H}_{29} \mathrm{NS}_{2}$ : calculated: $\mathrm{C}, 78.16 ; \mathrm{H}, 5.94 ; \mathrm{N}, 2.85 ; \mathrm{S}$, 13.04; found: C, 77.71; H, 6.04; N, 2.90; S, 13.35 .

\section{EDP4HP}

${ }^{1} \mathrm{H}$ NMR (500 MHz, $\left.\mathrm{CDCl}_{3}\right) \delta 8.70(\mathrm{~d}, J 9.2 \mathrm{~Hz}, 2 \mathrm{H})$, 8.21-8.04 (m, 16H), 7.35 (s, 2H), 4.25 (d, J 7.3, $1.4 \mathrm{~Hz}$, 2H), 2.13 (m, 1H), 1.54-1.25 (m, 8H), 0.99-0.89 (m, 6H); ${ }^{13} \mathrm{C} \mathrm{NMR}\left(125 \mathrm{MHz}, \mathrm{CDCl}_{3}\right) \delta 10.69,14.01,22.98,24.08$, 28.70, 30.71, 40.50, 51.38, 121.0, 122.7, 125.3, 126.7, 127.5, 127.9, 128.3, 128.8, 130.5, 132.2, 133.3, 141.1; elemental analysis for $\mathrm{C}_{48} \mathrm{H}_{37} \mathrm{NS}_{2}$ : calculated: $\mathrm{C}, 83.32 ; \mathrm{H}$, 5.39; N, 2.02; S, 9.27; found: C, 83.72; H, 5.29; N, 1.97; $\mathrm{S}, 9.02$.

\section{Results and Discussion}

The synthesis of EP4HP and EDP4HP is described in Scheme 1. EDP (1) and 1-bromopyrene (2) were synthesized according to the reported procedure as shown in the Experimental section. As shown in Scheme 1, the Buchwald-Hartwig reaction between 3,3'-dibromo2,2'-bithiophene and 2-ethylhexylamine catalyzed by $\mathrm{Pd}_{2}(\mathrm{dba})_{3}$ at $110^{\circ} \mathrm{C}$ for $24 \mathrm{~h}$ afforded compound $\mathbf{1}$ in a yield of $56 \%$. Compound 2 was generated with a yield of $94 \%$ from pyrene over bromination reaction. Then, the direct arylation reaction of EDP (1) and 1-bromopyrene (2) was carried out in the presence of the $\mathrm{Pd}(\mathrm{OAc})_{2}$ as the catalyst. This direct arylation mechanism based on the reaction of EDP and 1-bromopyrene which involved reductive elimination of the organic substituents 1-bromopyrene (R) and EDP (R') on a metal complex in the presence of ligand $(\mathrm{L}) \mathrm{P}(\mathrm{Cy})_{3}$. $\mathrm{HBF}_{4}$ formed the L(II)-M-RR'. The oxidative addition of 1-bromopyrene to L-Pd" gives LPdR(Br). Subsequently, the reaction undergoes transmetallation with a source of $\mathrm{R}^{-}$. In 


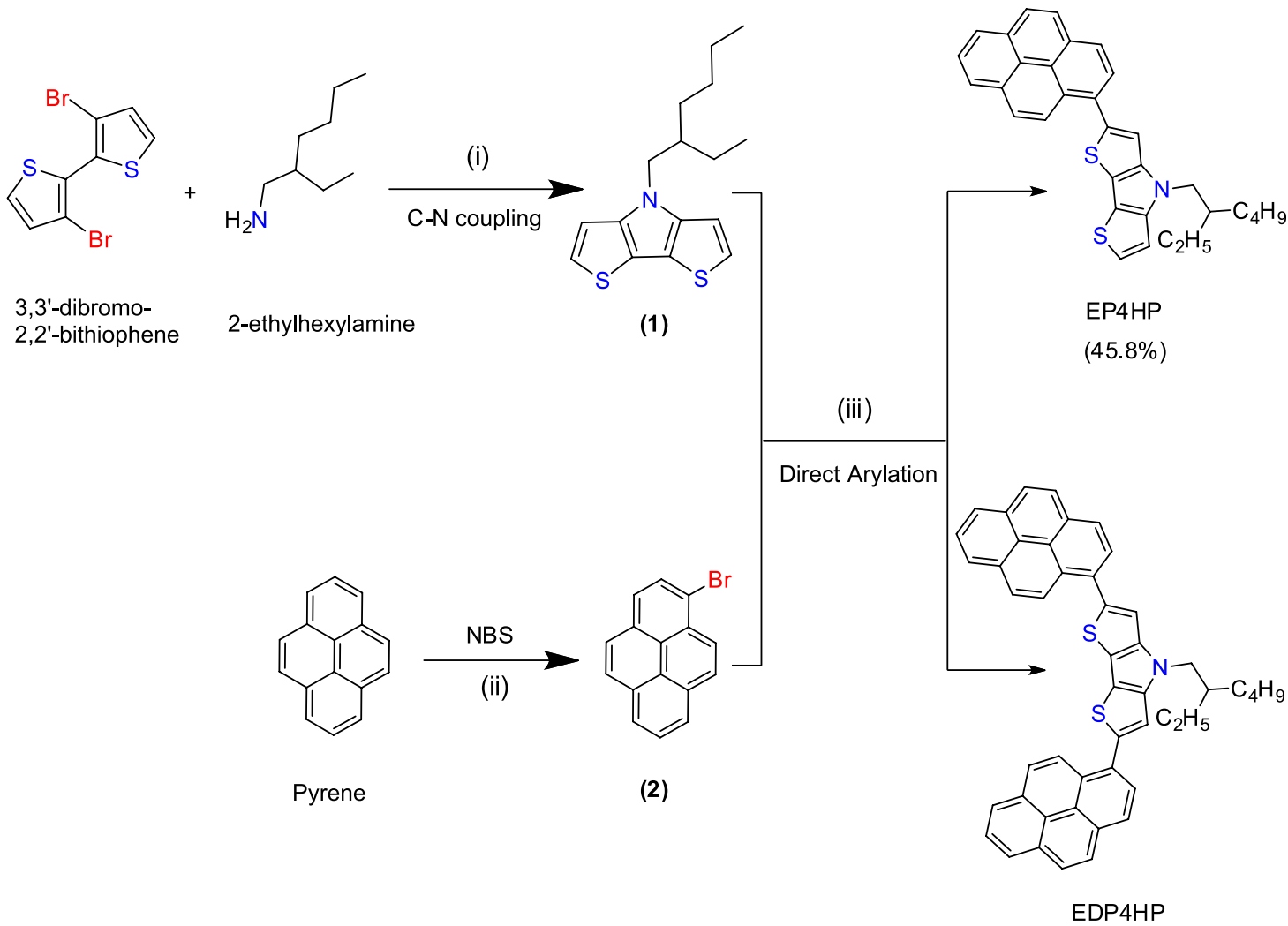

$(52 \%)$

Scheme 1. Synthesis for the conjugated molecular EP4HP and EDP4HP. Reagents and conditions: $(i) \mathrm{Pd}_{2}(\mathrm{dba})_{3}, \mathrm{BINAP}, \mathrm{NaO} t$-Bu, toluene, $110{ }^{\circ} \mathrm{C}$; (ii) DMF, r.t.; (iii) $\mathrm{Pd}(\mathrm{OAc})_{2}, \mathrm{P}(\mathrm{Cy})_{3} \cdot \mathrm{HBF}_{4}, \mathrm{Cs}_{2} \mathrm{CO}_{3}$, $\mathrm{PivOH}$, toluene, $110^{\circ} \mathrm{C}$.

the final stage, the reductive elimination of the two coupling 1-bromopyrene and EDP compounds regenerate the catalyst and give the final products EP4HP and EDP4HP.

The FTIR spectrum of EP4HP and EDP4HP compounds showed bands from 2868 to $3044 \mathrm{~cm}^{-1}$ assigned to the $\mathrm{C}-\mathrm{H}$ stretching vibrations of ethyl-hexyl group and $\mathrm{C}-\mathrm{H}$ linkage in aromatic structure. The band from 1516 to $1600 \mathrm{~cm}^{-1}$ is corresponding to $\mathrm{C}=\mathrm{C}$ stretching in aromatic and $\mathrm{C}-\mathrm{H}$ deformation vibrations. The peaks from 1020 to $1103 \mathrm{~cm}^{-1}$ indicate the existence of $\mathrm{C}-\mathrm{N}$. The band from 719 to $824 \mathrm{~cm}^{-1}$ is responsible for the $\mathrm{C}-\mathrm{S}$ stretching vibrations of thiophene structures.

The structures of the EP4HP and EDP4HP molecules were characterized via ${ }^{1} \mathrm{H}$ and ${ }^{13} \mathrm{C}$ NMR spectroscopies. In ${ }^{1} \mathrm{H}$ NMR of the EP4HP (Figure 2A), the peaks from 0.8 to $2.04 \mathrm{ppm}$ are attributed to the alkyl side chains. The peak $\mathrm{m}$ at $4.16 \mathrm{ppm}$ is corresponding to the proton of methylene linking to dithieno[3,2-b:2',3'-d]pyrrole moieties. The peak at $7.04 \mathrm{ppm}$ (peak 1) and the peak at $7.26 \mathrm{ppm}$ (peak j) are corresponding to the protons at positions 2 and 7 in the thiophene unit. In addition, the peak at $7.18 \mathrm{ppm}$ is attributed to the proton at position 8 in the thiophene unit that has not yet coupled with pyrene moieties. The peaks from 8.03 to $8.65 \mathrm{ppm}$ ascribed to the protons of pyrene unit in EP4HP molecules. In the case of EDP4HP (Figure 2B), the ${ }^{1} \mathrm{H}$ NMR spectrum exhibited all characteristic peaks corresponding to the chemical structure of EDP4HP. The peaks from 0.89 to $2.13 \mathrm{ppm}$ are presented for the alkyl side chains. The peak at 4.16 ppm (peak m, Figure 2B) is also attributed to the proton of methylene linking to dithieno[3,2-b:2', $\left.3^{\prime}-d\right]$ pyrrole moieties. It is interesting that the peak at $7.18 \mathrm{ppm}$ disappeared, this result suggested that the dithieno[3,2-b:2', $\left.3^{\prime}-d\right]$ pyrrole units have coupled completely with 1-bromopyrene to form EDP4HP. The peak at $7.35 \mathrm{ppm}$ (peak $\mathrm{j}$ ) is attributed to the protons at position 7 in the thiophene unit. The peaks from 8.03 to $8.65 \mathrm{ppm}$ are assigned to the protons of pyrene moieties. These results indicated that the direct arylation cross-coupling has been applied successfully to obtain the molecules of EP4HP and EDP4HP. However, the final products may contain some impurity compound such as 1-bromopyrene that appeared at 6.9 to $7.2 \mathrm{ppm}$, and the peaks at $5.25 \mathrm{ppm}$ corresponding to the proton of $\mathrm{CH}_{2} \mathrm{Cl}_{2}$ solvents which remains in the final product after purification.

UV-Vis spectroscopy has been used to investigate the absorption properties of molecules EP4HP and EDP4HP. Figure 3 showed the UV-Vis absorption spectra of molecules EP4HP and EDP4HP in dilute $\mathrm{CHCl}_{3}$ solution at different 


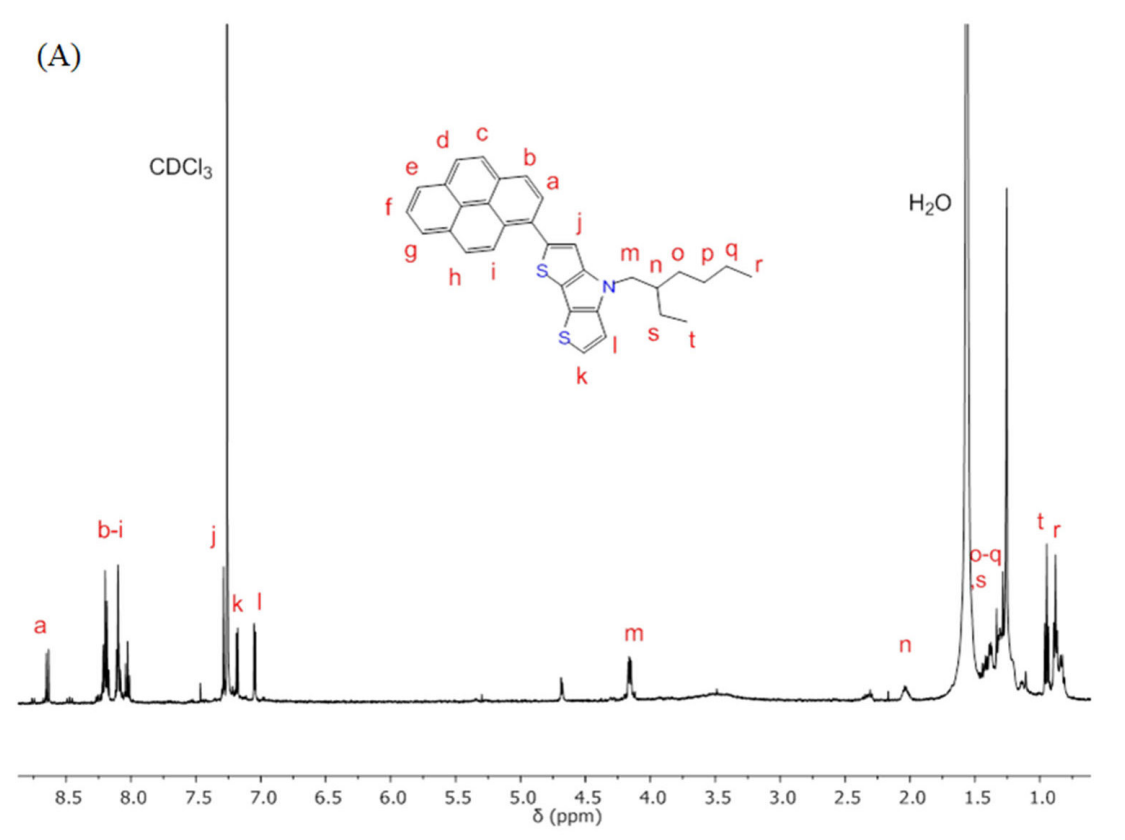

(B)

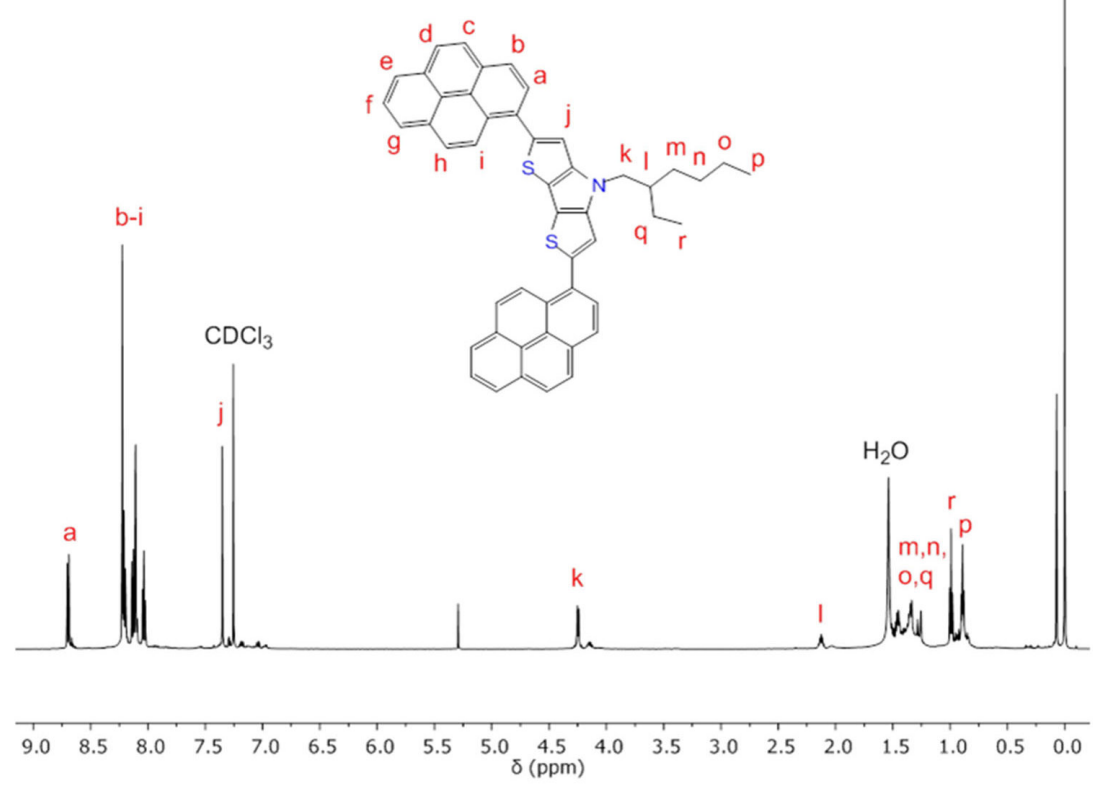

Figure 2. ${ }^{1} \mathrm{H}$ NMR spectra $\left(500 \mathrm{MHz}, \mathrm{CDCl}_{3}\right.$ ) of the molecules (A) EP4HP and (B) EDP4HP.

concentrations $(5,10,20,30 \mu \mathrm{M})$. In the case of EP4HP, absorption bands emerged at $232 \mathrm{~nm}$ with a shoulder of 261 and $370 \mathrm{~nm}$ which are corresponding to the absorption of 4-(2-ethylhexyl)-4H-dithieno[3,2- $b: 2^{\prime}, 3^{\prime}$ - $\left.d\right]$ pyrrole and pyrene moieties. The absorption band at $232 \mathrm{~nm}$ and shoulder of $261 \mathrm{~nm}$ was assigned to the electronic transition of dithienopyrrole, and the other at $370 \mathrm{~nm}$ attributed to the electronic transition of pyrene. The EDP4HP showed the absorption bands emerged at 232, 261, 325 and $410 \mathrm{~nm}$. The absorption bands of EDP4HP at $410 \mathrm{~nm}$ exhibited a red-shift compared to that of $370 \mathrm{~nm}$ of EP4HP, this result indicated that the extending of $\pi$ conjugation of EDP4HP enhances the red-shift absorption. Based on the lower energetic edge of the absorption, the optical bandgaps of EP4HP and EDP4HP molecules are 4.3 and $2.61 \mathrm{eV}$, respectively. Based on the Lambert-Beer law, the molar absorption coefficients $\varepsilon$ of EP4HP and EDP4HP at $232 \mathrm{~nm}$ were estimated with the value of 16464 and $24725 \mathrm{M}^{-1} \mathrm{~cm}^{-1}$, respectively, due to the $\pi$-extension of EDP4HP that leads to the higher molar absorption coefficient compared to those of EP4HP. 

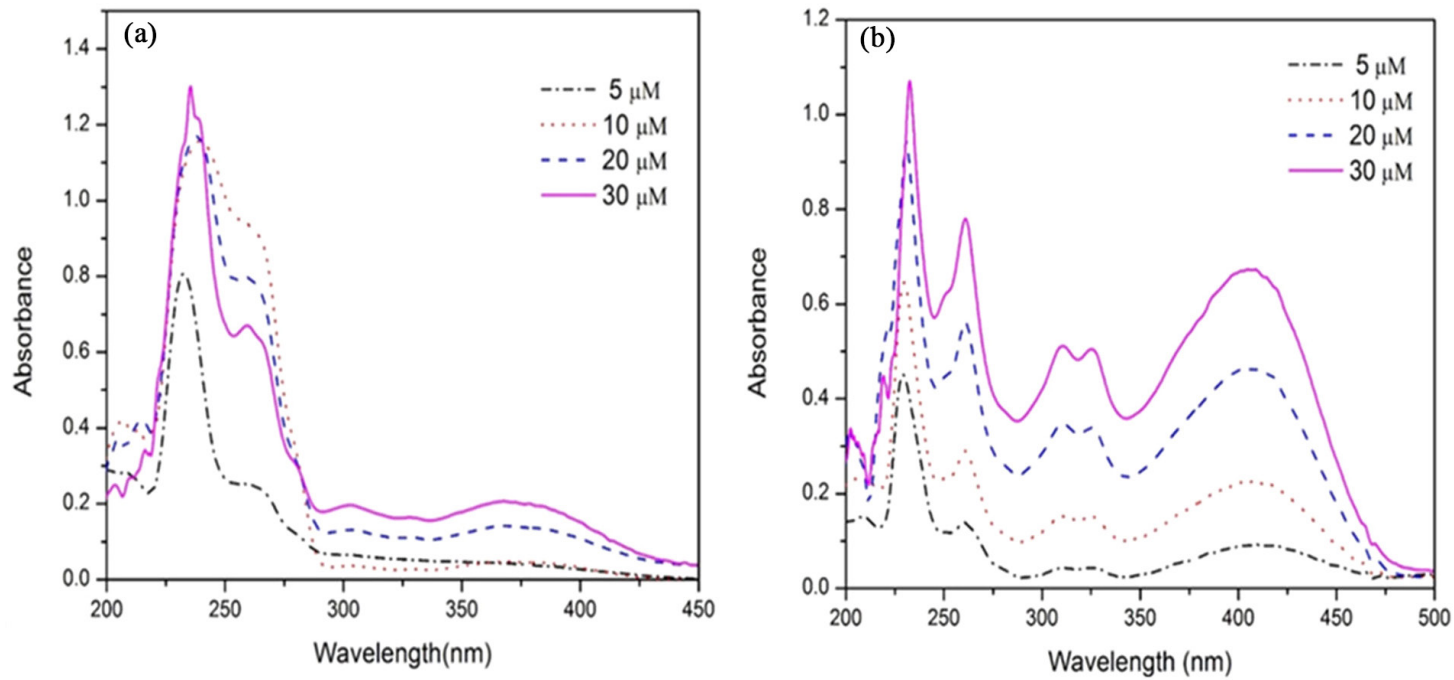

Figure 3. UV-Vis absorption spectra of (a) EP4HP and (b) EDP4HP at various concentrations in $\mathrm{CHCl}_{3}$.

The molecules EP4HP and EDP4HP have been applied for tracing of nitroaromatic pesticides via FRET mechanism. The molecules EP4HP and EDP4HP are molecules that associated with nitroaromatic via dipoledipole coupling. The fluorescence of EP4HP and EDP4HP in solution was excited at the wavelength of $365 \mathrm{~nm}$. The photoluminescence of EP4HP and EDP4HP has been investigated upon adding different amounts of herbicide mesotrione into the solution. The solutions of EP4HP and EDP4HP in $\mathrm{CHCl}_{3}$ were prepared with concentration $\left(\mathrm{C}_{\mathrm{M}}\right)$ of $1.0 \mu \mathrm{M}$ as the host stock solution, followed by the addition of different amounts $(0-75 \mu \mathrm{M})$ of mesotrione. It is interesting that the results exhibited that fluorescence intensities decreased gradually with the increase of the concentration of mesotrione compound. This phenomenon suggested that the binding between mesotrione with EP4HP and EDP4HP causes the fluorescence quenching. Figures $4 \mathrm{a}$ and $4 \mathrm{~b}$ exhibited the fluorescence quenching of EP4HP and EDP4HP in the presence of mesotrione compound. At the concentration of $1 \mu \mathrm{M}$ of mesotrione, the fluorescence intensity of the EP4HP and EDP4HP decreased 200 a.u. At the concentration of $75 \mu \mathrm{M}$ of mesotrione, the fluorescence intensity of EP4HP decreased 1000 a.u., while the fluorescence intensity of EDP4HP decreased 2750 a.u. that caused the color changing of EDP4HP solution from bright green to dark green which can be observed by naked eyes.

Figures $5 \mathrm{a}$ and $5 \mathrm{c}$ performed the fluorescence ratiometric responses of EP4HP and EDP4HP to trace mesotrione analyte, respectively. Figure 5a showed the PL emission spectrum of EP4HP solution $\left(\mathrm{C}_{\mathrm{M}}=1 \mu \mathrm{M}\right)$ upon the incremental addition of mesotrione with different concentrations $\left(\mathrm{C}_{\mathrm{M}}=0-75 \mu \mathrm{M}\right)$. The EP4HP exhibited the emission peak at $500 \mathrm{~nm}$ under excited wavelength at $365 \mathrm{~nm}$. At $1 \mu \mathrm{M}$ of mesotrione, the fluorescence intensity of the molecules EP4HP solution decreased from
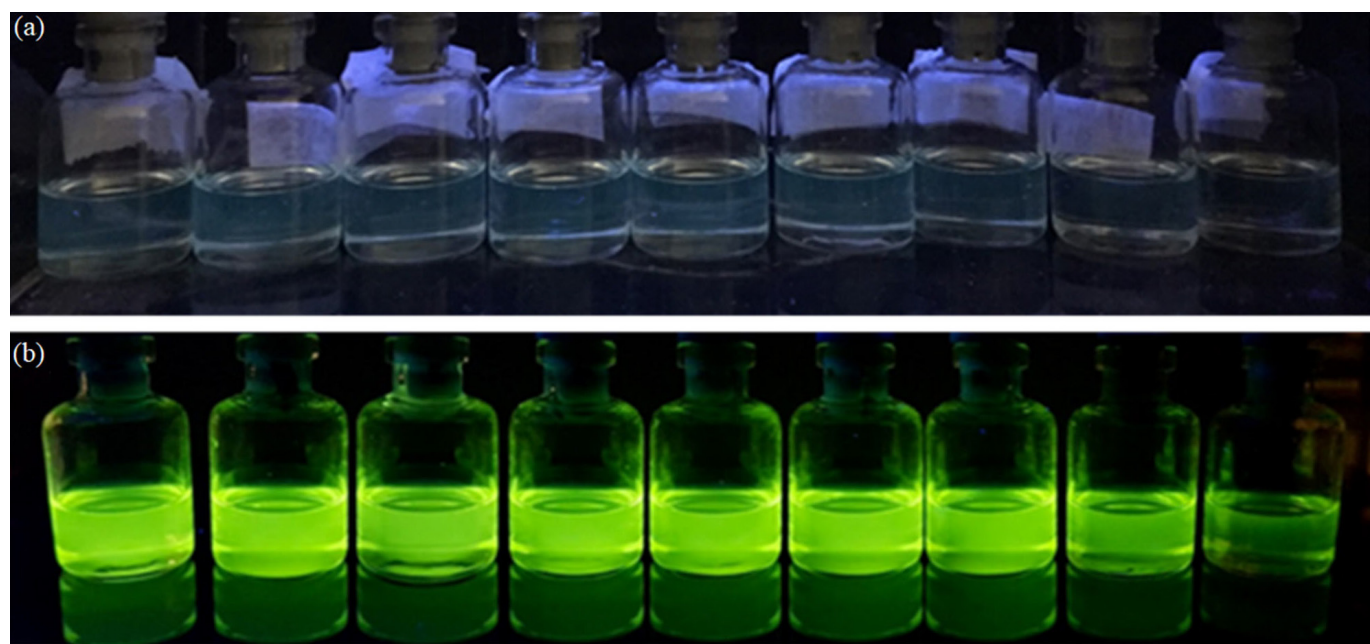

Figure 4. Fluorescence quenching of (a) EP4HP in $\mathrm{CHCl}_{3}(1 \mu \mathrm{M})$ and (b) EDP4HP in $\mathrm{CHCl}_{3}(1 \mu \mathrm{M})$ upon addition of mesotrione (0-75 $\left.\mu \mathrm{M}\right)$. 
1150 to 1000 a.u. that is estimated about $9.1 \%$. When concentration of mesotrione was increased to $75 \mu \mathrm{M}$, the fluorescence intensity of EP4HP decreased to 200 a.u. which is corresponding to $82.6 \%$ decreasing in fluorescence intensity. In the case of EDP4HP, it showed the emission peak at $540 \mathrm{~nm}$ under excited at $365 \mathrm{~nm}$ (Figure 5b). At $1 \mu \mathrm{M}$ of mesotrione, the fluorescence intensity of the EDP4HP solution decreased $10.7 \%$ comparing to the initial fluorescence intensity. Since the mesotrione increased to $75 \mu \mathrm{M}$, the fluorescence intensity of EDP4HP solution was decreased to 500 a.u. which corresponds to $84.6 \%$ decreasing in fluorescence intensity. According to the World Health Organization-Food and Agriculture Organization (WHOFAO), the mesotrione in agriculture can be acceptable daily intake less than $0.5 \mathrm{mg} \mathrm{kg}^{-1}$, both EP4HP and EDP4HP can be used to trace the mesotrione at $\mathrm{C}_{\mathrm{M}}=1 \mu \mathrm{M}$ which corresponds to the $0.5 \mathrm{mg} \mathrm{kg}^{-1}$ of mesotrione that is suitable as a chemosensor. In addition, the fluorescence intensity of EDP4HP is much higher than those of EP4HP due to the expansion of $\pi$ conjugated systems.

The Stern-Volmer constant $\left(\mathrm{K}_{\mathrm{SV}}\right)$ of EP4HP and EDP4HP were calculated to inspect a more complete understanding of the fluorescence quenching efficiency based on the data of fluorescence emission spectrums (Figure 4). The Stern-Volmer equation is given as:
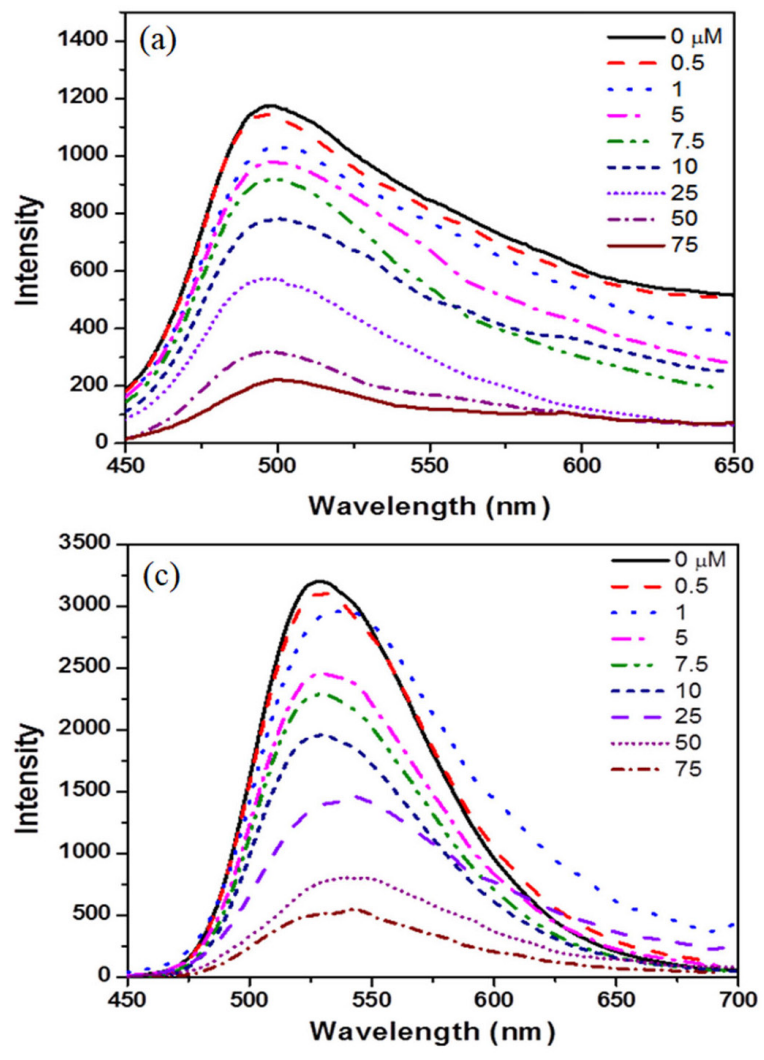

$\frac{\mathrm{I}_{0}}{\mathrm{I}}=1+\mathrm{K}_{\mathrm{SV}} \mathrm{C}_{\mathrm{A}}$

where $I_{0}$ is fluorescence intensity of solution with the absence of analyte (quencher A), and I is fluorescence intensity of solution with the presence of the analyte (quencher $\mathrm{A}$ ); $\mathrm{C}_{\mathrm{A}}$ is the molar concentration of the analyte, and $\mathrm{K}_{\mathrm{SV}}$ denotes the Stern-Volmer quenching constant. The quenching efficiency by mesotrione of EP4HP and EDP4HP determined from the Stern-Volmer plot had linear responses to this equation with correlation coefficients of 0.994 and 0.9723 , respectively. The calculated SternVolmer constant $\left(\mathrm{K}_{\mathrm{SV}}\right)$ of EP4HP was $5570 \mathrm{M}^{-1}$ with the limit of detection (LOD) towards mesotrione down to $1 \mu \mathrm{M}$ based on the standard method reported. ${ }^{35}$ Similarly, the Stern-Volmer constants $\left(\mathrm{K}_{\mathrm{SV}}\right)$ and the LOD of EDP4HP toward mesotrione were $6520 \mathrm{M}^{-1}$ and $1 \mu \mathrm{M}$, respectively. Based on these results, it is considered that the interactions between EDP4HP and EP4HP with mesotrione caused the fluorescence quenching of the conjugated molecules. The static quenching mechanism of molecules EP4HP and EDP4HP was proposed in Figure 6. ${ }^{36,37}$

To get more insights into the mechanism of fluorescence quenching, the mixing of the EP4HP and EDP4HP with mesotrione were characterized for UV-Vis and

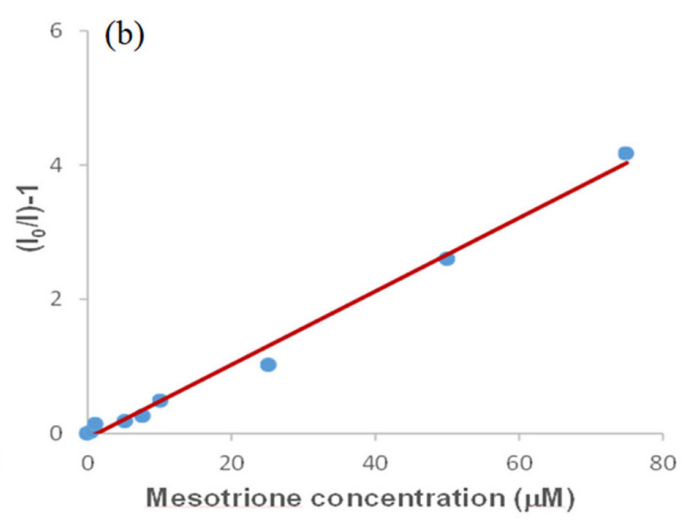

(d)

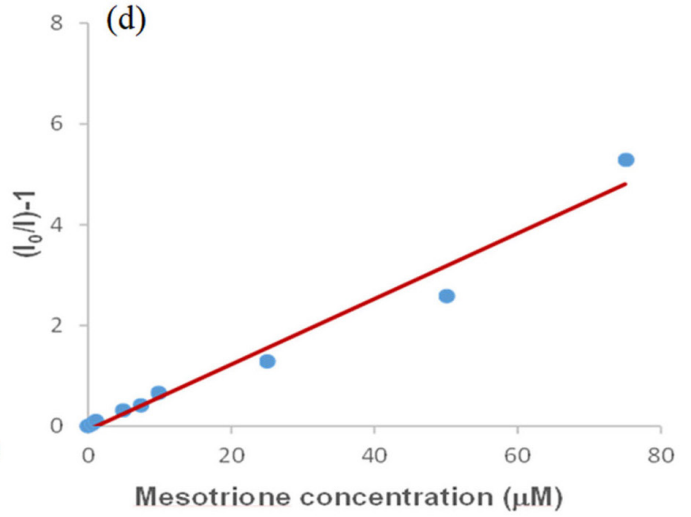

Figure 5. (a) Fluorescence emission spectra of EP4HP and (c) EDP4HP in $\mathrm{CHCl}_{3}(1 \mu \mathrm{M})$ with concentration increase of mesotrione; and the corresponding Stern-Volmer plot of (b) EP4HP and (d) EDP4HP. 


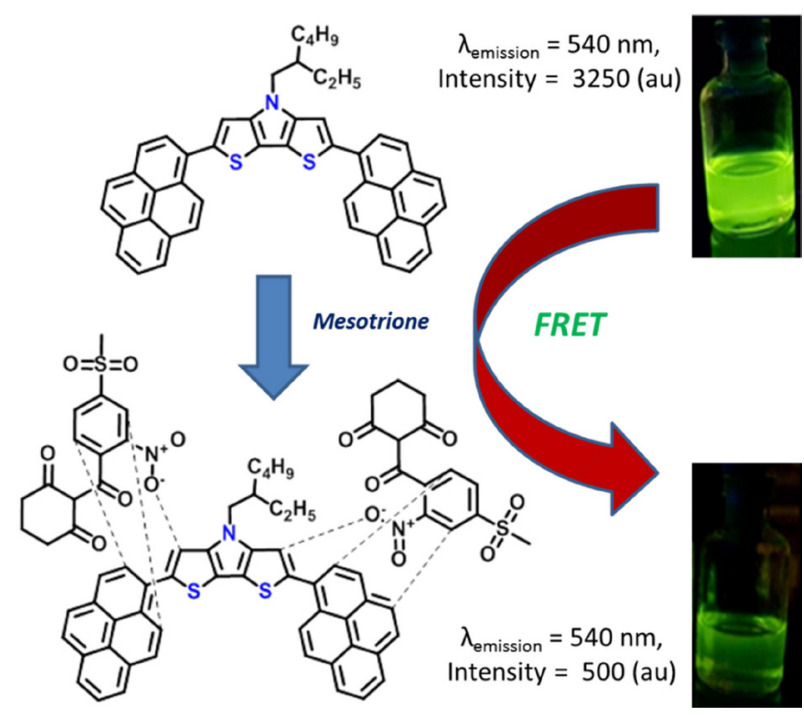

Figure 6. Proposed schematic diagram of EDP4HP interaction with mesotrione.

electrochemical characterization. To confirm the influence of mesotrione on fluorescence quenching of EDP4HP via FRET mechanism, the absorption spectra of EDP4HP solution in the absence and in the presence of mesotrione have been compared as shown in Figure 7. The UV-Vis of EDP4HP solution showed the absorption peak at $410 \mathrm{~nm}$ that was red-shifted compared with the absorption of EDP4HP with mesotrione $\left(\mathrm{C}_{\mathrm{M}}=1 \mu \mathrm{M}\right)$ solution which showed the absorption peak at $320 \mathrm{~nm}$. In the case of EP4HP, the UV-Vis spectra of EP4HP with mesotrione exhibited the absorption at $305 \mathrm{~nm}$ while the absorption of EP4HP is around $232 \mathrm{~nm}$ with shoulder of $261 \mathrm{~nm}$. This phenomenon can be attributed to the $\pi-\pi$ conjugated intermolecular stacking that was disturbed in the presence of mesotrione moieties by the formation of the linkage as van der Waals forces due to electrostatic interactions between EDP4HP and the nitrogen groups of mesotrione compound via the donor-acceptor interactions between electron-deficient nitro groups and electron-rich dithieno[3,2-b:2',3'-d]pyrrole or pyrene moieties. In addition, the $\pi-\pi$ interaction formed the complexation of EP4HP/EDP4HP with the mesotrione via Willem Hendrik Keesom interaction due to pyrene units with phenyl moieties due to permanent dipoles of molecules.

To further confirm the fluorescence quenching effect of EDP4HP induced by mesotrione moieties, we have characterized and compared the electrochemical comparison of EDP4HP with and without mesotrione by the cyclic voltammetry technique. The solutions of EDP4HP and EDP4HP in acetonitrile with mesotrione were prepared with $0.1 \mathrm{M} \mathrm{TBAPF}_{6}$. Figure 8 presents the cyclic voltammetry of EDP4HP and EDP4HP with mesotrione in acetonitrile in the range of $0-2.0 \mathrm{~V}$ potential
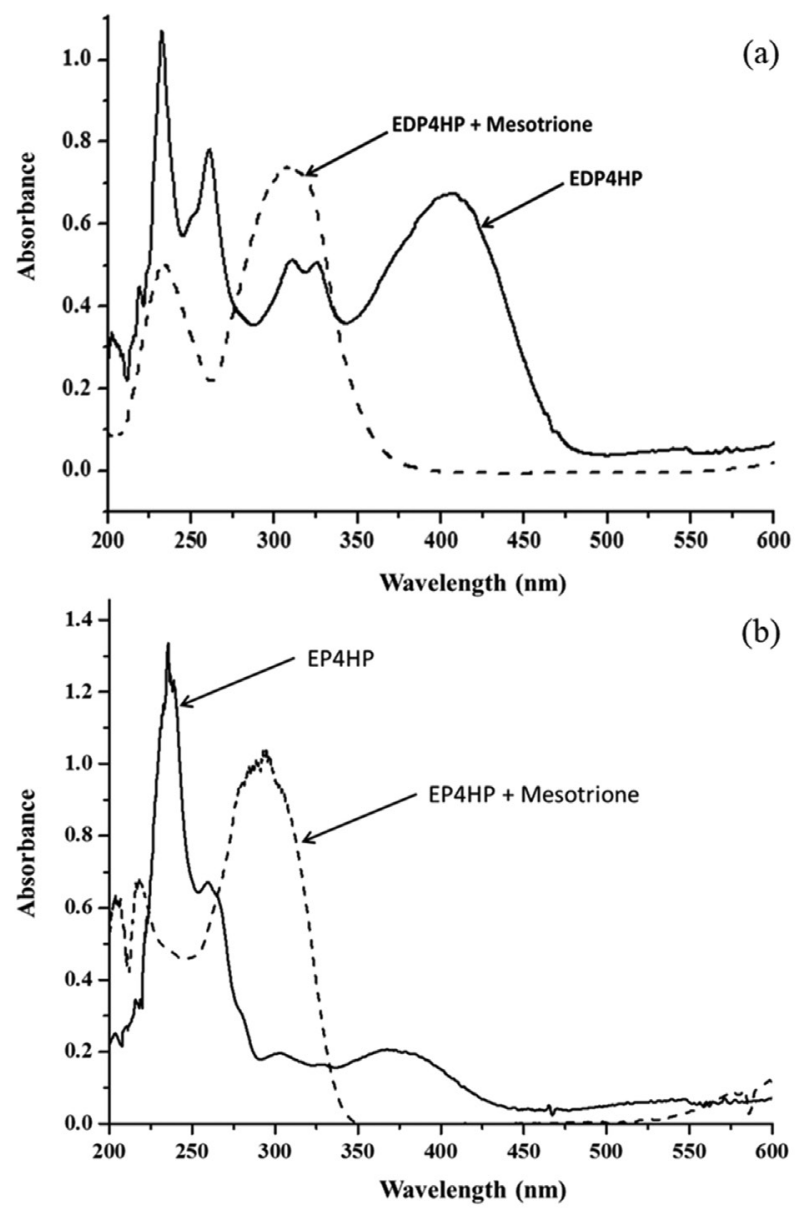

Figure 7. UV-Vis absorption spectra of (a) EDP4HP/EDP4HP with mesotrione and (b) EP4HP/EP4HP with mesotrione in $\mathrm{CHCl}_{3}$.

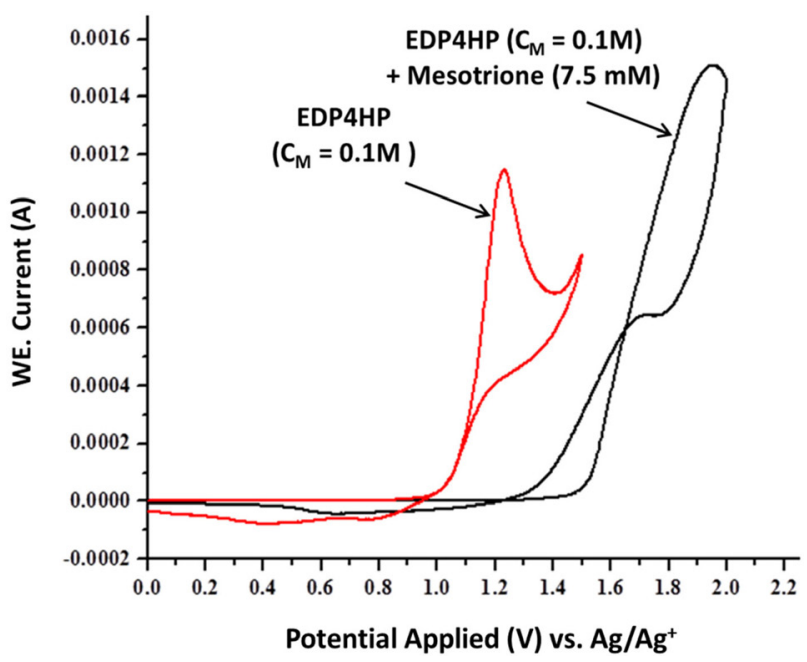

Figure 8. Cyclic voltammograms of EDP4HP and EDP4HP with mesotrione in acetonitrile.

scanning. The EDP4HP exhibited the oxidation peak at $1.2 \mathrm{~V}$ whereas the EDP4HP with mesotrione showed a higher oxidation peak at $1.8 \mathrm{~V}$. This result confirmed that the intermolecular stacking based on $\pi-\pi$ conjugated of EDP4HP was interrupted by mesotrione moieties that 
lead to the lower HOMO (highest occupied molecular orbital) energy level.

In addition, cellulose papers were coated with the EDP4HP by dip-coating into the solution of triad EDP4HP $\left(\mathrm{C}_{\mathrm{M}}=1 \mu \mathrm{M}\right)$ and used to trace the mesotrione (Figure 9). The mesotrione solution in different concentrations was added onto the cellulose paper sample. The samples displayed sapphire color luminescence under UV irradiation while the papers exhibited the dark color area in the precence of mesotrione. Therefore, the EDP4HP is suitable to trace the mesotrione used in an agriculture product with high contents.
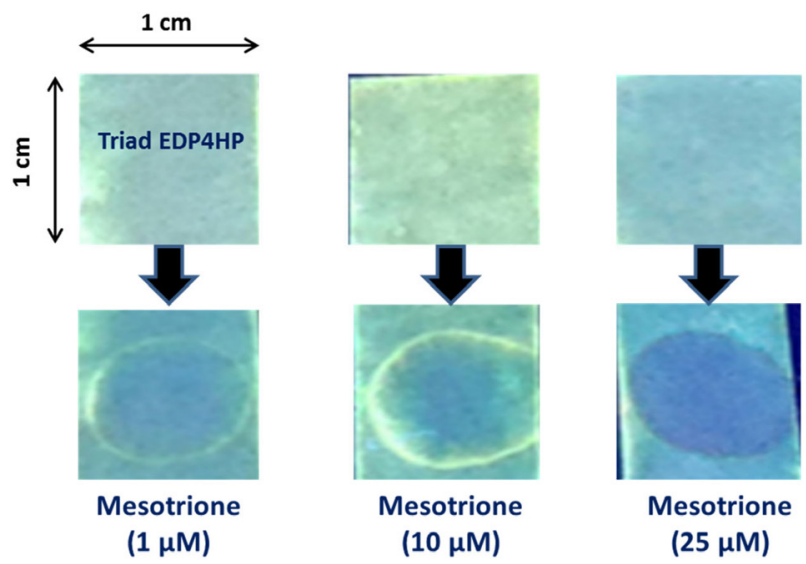

Figure 9. Image of EDP4HP coated on the cellulose paper under UV irradiation $(365 \mathrm{~nm})$.

\section{Conclusions}

In conclusion, the conjugated molecules based on pyrene and 4-(2-ethylhexyl)-2-(pyren-1-yl)-4H-dithieno $\left[3,2-b: 2^{\prime}, 3^{\prime}-d\right]$ pyrrole have been successfully synthesized via direct arylation reaction. The molar absorption coefficient of EP4HP and EDP4HP was 16464 and $24725 \mathrm{M}^{-1} \mathrm{~cm}^{-1}$, respectively. The obtained molecules have been used for tracing mesotrione compound through FRET with high sensitivity of $\mathrm{K}_{\mathrm{SV}}$ of 5570 and $6520 \mathrm{M}^{-1}$ for EP4HP and EDP4HP, respectively. The materials based on the EP4HP and EDP4HP compounds are promising candidates for technical application for mesotrione detection as a chemosensors.

\section{Supplementary Information}

Supplementary data are available free of charge at http://jbcs.sbq.org.br as PDF file.

\section{Acknowlegments}

This research was fully supported by the Ho Chi Minh University of Technology Project "To-KTHH-2020-02".

\section{Author Contributions}

Bao K. Doan, Cam H. T. Nguyen, Thao T. Bui and Tung V. T. Tran were responsible for data curation, formal analysis, investigation; Ha P. K. Huynh, Quoc-Thiet Nguyen, Son T. Cu, Le-Thu T. Nguyen, Chau D. Tran, Hai L. Tran were responsible for conceptualization, project administration, resources, software, validation, visualization; Phong T. Mai was responsible for conceptualization, editing and supervision; Ha T. Nguyen was responsible for conceptualization, investigation, validation, project administration, writing original manuscript and editing.

\section{References}

1. UN Human Rights Experts Call for Global Treaty to Regulate Dangerous Pesticides; https://news.un.org/en/ story/2017/03/552872-un-human-rights-experts-call-globaltreaty-regulate-dangerous-pesticides, accessed in February 2022.

2. Ju, K. S.; Parales, R. E.; Microbiol. Mol. Biol. Rev. 2010, 74, 250.

3. He, L.; Luo, X.; Xie, H.; Wang, C.; Jiang, X.; Lu, K.; Anal. Chim. Acta 2009, 655, 52.

4. Gao, S.; Wu, G.; Li, X.; Chen, J.; Wu, Y.; Wang, J.; Zhang, Z.; J. Anal. Test. 2018, 2, 322.

5. Guan, S. H.; Huang, M. W.; Li, X.; Cai, Q.; Anal. Lett. 2018, 51,613 .

6. Deroco, P. B.; Lourencao, B. C.; Fatibello-Filho, O.; Microchem. J. 2017, 133, 188.

7. Vakurov, A.; Simpson, C.; Daly, C.; Gibson, T.; Millner, P.; Biosens. Bioelectron. 2004, 20, 1118.

8. Toal, S. J.; Trogler, W. C.; J. Mater. Chem. 2006, 16, 2871.

9. Zhao, Z.; Zhang, F.; Zhang, Z.; Spectrochim. Acta, Part A 2018, 199, 96.

10. Hu, Y.; Wang, J.; Wu, Y.; Anal. Methods 2019, 11, 5337.

11. Mallard-Favier, I.; Blach, P.; Cazier, F.; Delattre, F.; Carbohydr. Res. 2009, 344, 161.

12. Kumar, P.; Paul, A.; Deep, A.; Anal. Methods 2014, 6, 4095.

13. Hergert, M.; Bender, M.; Seehafer, K.; Bunz, U. H.; Chem. - Eur. J. 2018, 24, 3132.

14. Sun, X.; Liu, Y.; Niu, N.; Chen, L.; Anal. Bioanal. Chem. 2019, $411,5519$.

15. Zhang, B.; Li, B.; Wang, Z.; ACS Sens. 2020, 5, 162.

16. Hussain, S. A.; Dey, D.; Chakraborty, S.; Saha, J.; Roy, A. D.; Chakraborty, S.; Debnath, P.; Bhattacharjee, D.; arXiv, 2014, available at https://arxiv.org/ftp/arxiv/papers/1408/1408.6559. pdf, accessed in February 2022.

17. Wu, S.; Li, D.; Gao, Z.; Wang, J.; Microchim. Acta 2017, 184, 4383.

18. Ding, D.; Li, K.; Liu, B.; Tang, B. Z.; Acc. Chem. Res. 2013, 46, 2441. 
19. Yang, Z.; Mao, Z.; Xie, Z.; Zhang, Y.; Liu, S.; Zhao, J.; Xu, J.; Chi, Z.; Aldred, M. P.; Chem. Soc. Rev. 2017, 46, 915.

20. Zhao, Z.; Gao, S.; Zheng, X.; Zhang, P.; Wu, W.; Kwok, R. T.; Xiong, Y.; Leung, N. L.; Chen, Y.; Gao, X.; Adv. Funct. Mater. 2018, 28, 1705609.

21. Mishra, A.; Bäuerle, P.; Angew. Chem., Int. Ed. 2012, 51, 2020.

22. Peng, Z.; Feng, X.; Tong, B.; Chen, D.; Shi, J.; Zhi, J.; Dong, Y.; Sens. Actuators, B 2016, 232, 264.

23. Cai, Y.; Fang, J.; Wang, B.; Zhang, F.; Shao, G.; Liu, Y.; Sens. Actuators, B 2019, 292, 156.

24. Hong, Y.; Lam, J. W.; Tang, B. Z.; Chem. Commun. 2009, 4332.

25. Li, H.; Chang, J.; Gai, P.; Li, F.; ACS Appl. Mater. Interfaces 2018, 10, 4561.

26. Alidağı, H. A.; Tümay, S. O.; Şenocak, A.; Yeşilot, S.; Dyes Pigm. 2018, 153, 172.

27. Vollmann, H.; Becker, H.; Corell, M.; Streeck, H.; Justus Liebigs Ann. Chem. 1937, 531, 1.

28. Merz, J.; Dietz, M.; Vonhausen, Y.; Wöber, F.; Friedrich, A.; Sieh, D.; Krummenacher, I.; Braunschweig, H.; Moos, M.; Holzapfel, M.; Lambert, C.; Marder, T. B.; Chem. - Eur. J. 2020, 26, 438 .

29. Kovalev, I.; Sadieva, L.; Taniya, O.; Yurk, V.; Minin, A.; Kopchuk, D.; Zyryanov, G.; Charushin, V.; Chupakhin, O.; Chim. Techno Acta 2021, 8, 20218209.
30. Venkatramaiah, N.; Firmino, A. D.; Paz, F. A. A.; Tome, J. P.; Chem. Commun. 2014, 50, 9683.

31. Kovalev, I. S.; Taniya, O. S.; Slovesnova, N. V.; Kim, G. A.; Santra, S.; Zyryanov, G. V.; Kopchuk, D. S.; Majee, A.; Charushin, V. N.; Chupakhin, O. N.; Chem. - Asian J. 2016, 11,775 .

32. Verbitskiy, E. V.; Baranova, A. A.; Lugovik, K. I.; Khokhlov, K. O.; Chuvashov, R. D.; Dinastiya, E. M.; Rusinov, G. L.; Chupakhin, O. N.; Charushin, V. N.; J. Iran. Chem. Soc. 2018, $15,787$.

33. He, G.; Yan, N.; Yang, J.; Wang, H.; Ding, L.; Yin, S.; Fang, Y.; Macromolecules 2011, 44, 4759.

34. Kolanji, K.; Baumgarten, M.; Chemistry 2020, 26, 3626.

35. Shrivastava, A.; Gupta, V. B.; Chron. Young Sci. 2011, 2, 21.

36. Neto, B. A. D.; Corrêa, J. R.; Carvalho, P. H. P. R.; Santos, D. C. B. D.; Guido, B. C.; Gatto, C. C.; de Oliveira, H. C. B.; Fasciotti, M.; Eberlin, M. N.; da Silva Jr., E. N.; J. Braz. Chem. Soc. 2012, 23, 770.

37. Chaves, O. A.; Teixeira, F. S. M.; Guimarães, H. A.; Braz-Filho, R.; Vieira, I. J. C.; Sant'Anna, C. M. R.; Netto-Ferreira, J. C.; Cesarin-Sobrinho, D.; Ferreira, A. B. B.; J. Braz. Chem. Soc. 2017, 28, 1229.
Submitted: October 25, 2021

Published online: February 17, 2022 